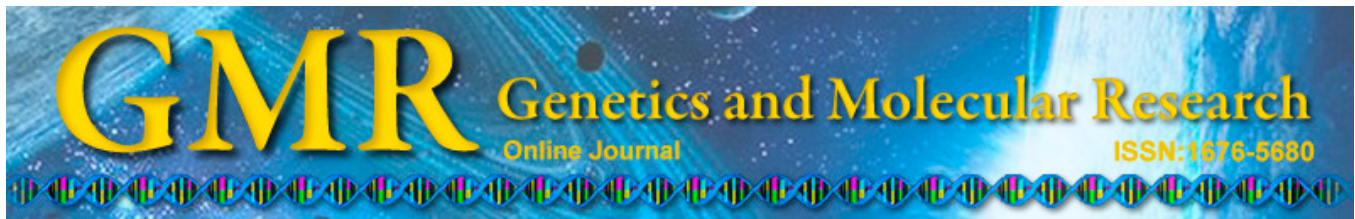

\title{
Association between the CYP1A1 polymorphisms and hepatocellular carcinoma: a meta-analysis
}

\author{
B.W. Yu ${ }^{1 *}$, L.Q. Zhang ${ }^{1 *}$, X.L. Teng ${ }^{1}$, Y. Zhang ${ }^{1}$, L.B. Zou ${ }^{2}$ and H.Y. Ying ${ }^{3}$ \\ 'Department of Clinical Laboratory, Jinhua People's Hospital, Jinhua, China. \\ ${ }^{2}$ Medicine Reproductive Centre, Jinhua People's Hospital, Jinhua, China. \\ ${ }^{3}$ Department of Clinical Laboratory, Jinhua Center Hospital, Jinhua, China. \\ *These authors contributed equally to this study. \\ Corresponding author: H.Y. Ying \\ E-mail: yinghy100@126.com
}

Genet. Mol. Res. 14 (1): 1076-1084 (2015)

Received May 25, 2014

Accepted September 11, 2014

Published February 6, 2015

DOI http://dx.doi.org/10.4238/2015.February.6.11

\begin{abstract}
Numerous studies have evaluated the association between CYP1A1 gene polymorphisms and hepatocellular carcinoma (HCC) risk. However, the specific association is still controversial. The aim of our study was to clarify the effects of CYP1A1 gene polymorphisms (3801 T $>\mathrm{C}$ and $\mathrm{A} 2455 \mathrm{G}$ ) on $\mathrm{HCC}$ risk by conducting a meta-analysis. We conducted searches of the literature published in PubMed and EMBASE databases up to April 2014. We estimated the pooled odds ratio with its $95 \%$ confidence interval to assess the association using a fixed or random-effects model. Publication bias was investigated by the Begg funnel plot. Meta-analysis was performed using the STATA package version 12.0. Meta-analysis results showed no significant association between the CYP1A1 $3801 \mathrm{~T}>\mathrm{C}$ polymorphism and $\mathrm{HCC}$ risk. In a subgroup analysis by nationality, we found a significant association between $3801 \mathrm{~T}>\mathrm{C}$ polymorphism and HCC risk in Asians
\end{abstract}


(TT vs TC: $\mathrm{OR}=0.77,95 \% \mathrm{CI}=0.60-0.99$ ). As for A2455G, the metaanalysis indicated no significant association between the CYP1A1 A2455G polymorphism and $\mathrm{HCC}$ risk. In conclusion, the $3801 \mathrm{~T}>\mathrm{C}$ polymorphism in the CYP1A1 gene may be related to increased risk of $\mathrm{HCC}$ in Asians. Conclusive evidence on the effects of the variants in HCC should be addressed in further studies.

Key words: CYP1A1; Gene polymorphism; Meta-analysis; Hepatocellular carcinoma

\section{INTRODUCTION}

Hepatocellular carcinoma (HCC) is the third leading cause of cancer mortality in the world (Parkin et al., 2001). It had an estimated global incidence of more than 500,000 cases in the year 2000, and its incidence is rising in many countries. The severity of HCC and the lack of effective treatment strategies make the disease a major challenge. This disease is strongly associated with several risk factors, including alcoholism, hepatitis B and C, liver cirrhosis, hemochromatosis, aflatoxin and type 2 diabetes (Niwa et al., 2005). In addition, epidemiological studies provide strong evidence that genetic factors are important in the pathogenesis of HCC (Liu et al., 2014).

Cytochrome P450s (CYP450s) are heme-containing enzymes important in the phase I-dependent metabolism of drugs and other xenobiotics (Rodriguez-Antona et al., 2006). CYP450 1A1 (CYP1A1) is mainly expressed extrahepatically, especially in epithelial tissues, and it metabolizes several suspected procarcinogens, particularly polycyclic aromatic hydrocarbons (PAHs), into highly reactive intermediates (Guengerich and Shimada, 1998), which can form DNA adducts, which, if unrepaired, can initiate or accelerate carcinogenesis (Zhan et al., 2011). Although PAHs are ubiquitous in the environment, notable sources of exposure that cause the greatest concern include smoking, air pollution, diet, and certain occupations (Shimada et al., 2006).

The CYP1A1 gene has seven exons and is located on chromosome 15q22-24. Several polymorphisms of the CYP1A1 gene have been shown to be associated with cancer risk. Among these polymorphisms, the most commonly studied is the $3801 \mathrm{~T}>\mathrm{C}$ polymorphism (also referred to as 2A, m1, or rs4646903, which is characterized by a $\mathrm{T}$ to $\mathrm{C}$ mutation at nucleotide 3801 in the 30 flanking region of the CYP1A1 gene) and the A2455G polymorphism (also known as CYP1A1-E7, CYP1A1*2C, m2, or rs1048943, which is characterized by an A to $\mathrm{G}$ transition). Epidemiological studies have demonstrated that the $3801 \mathrm{~T}>\mathrm{C}$ and $\mathrm{A} 2455 \mathrm{G}$ polymorphisms can alter the level of gene expression or messenger RNA stability, resulting in a highly inducible activity of the enzyme (Shah et al., 2009).

To date, several studies have investigated the relationship between the CYP1A1 3801 $\mathrm{T}>\mathrm{C}$ and $\mathrm{A} 2455 \mathrm{G}$ polymorphisms and $\mathrm{HCC}$ risk, but the results have been inconsistent. Moreover, no meta-analysis data on the correlation of the polymorphisms with susceptibility to HCC is currently available. Therefore, to derive a more precise overall effect, the present study aimed to evaluate the association between the CYP1A1 $3801 \mathrm{~T}>\mathrm{C}$ and A2455G polymorphisms and susceptibility to HCC by performing a systematic review and meta-analysis of the literature. 


\section{MATERIAL AND METHODS}

\section{Selection of studies}

The data were independently gathered in duplicate by two investigators on the basis of a standard protocol (W. Yu and L.Q. Zhang). All search queries were updated until April 2014 using the following search strategy: ("HCC" or "CYP1A1") and ("3801 T>C" or "A2455G" or "genotype" or "polymorphism"). In addition, the reference lists of the included articles included and relevant meta-analyses were manually searched. Studies reported by the same authors were checked for possible overlapping participant groups. No restrictions were applied as to language.

\section{Inclusion and exclusion criteria}

Studies were included in this meta-analysis if they satisfied the inclusion criteria as follows: 1) case-control studies; 2) studies assessing the association of CYP1A13801 T $>\mathrm{C}$ or A2455G polymorphism with HCC risk; 3) providing sufficient information for estimating odds ratio (OR) with its $95 \%$ confidence interval $(95 \% \mathrm{CI})$; and 4$)$ providing available data to acquire genotype frequency of CYP1A1 $3801 \mathrm{~T}>\mathrm{C}$ or A2455G polymorphism. Major exclusion criteria were: 1) no control population, 2) no available genotype frequency, and 3) duplicated studies.

\section{Data extraction}

The following characteristics were collected from each study: first author, year of publication, region of the first or corresponding author, ethnicity, number of cases and controls, number of genotypes and evidence of Hardy-Weinberg equilibrium (HWE), which are listed in Table 1. Different ethnicities were categorized as Asian and Caucasian. If original genotype frequency data were unavailable in relevant articles, an email was sent to the corresponding author for additional data. For conflicting evaluations, an agreement was reached following a discussion.

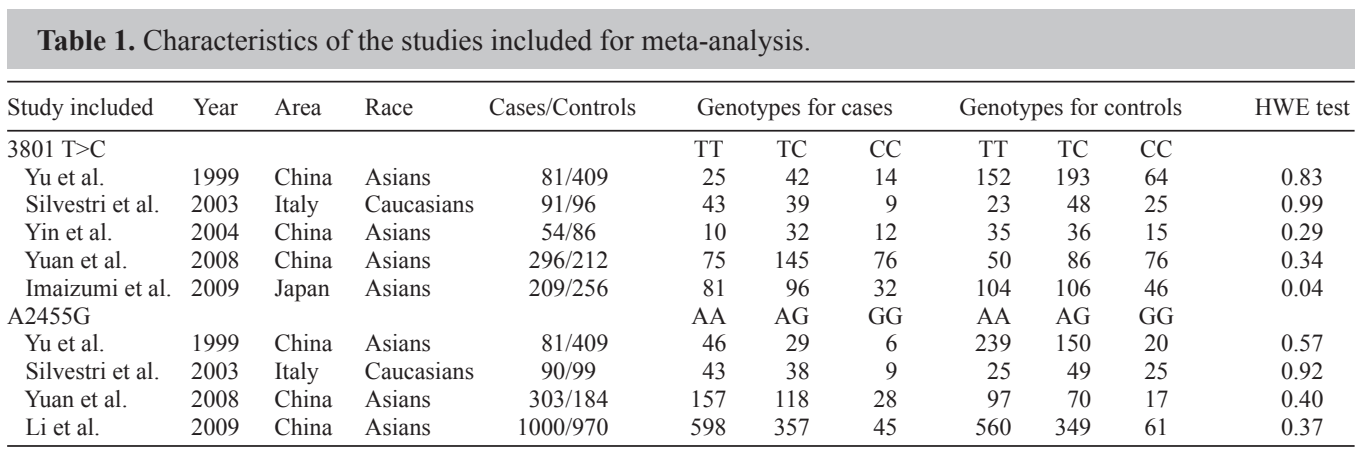

\section{Statistical analysis}

Meta-analysis was performed using the STATA package version 12.0 (Stata Corporation, College Station, TX, USA). OR and corresponding 95\% CI were used to assess the degree of association between CYP1A1 gene polymorphisms (3801 T $>$ C and A2455G) and 
HCC under a homozygote comparison (AA vs aa), a heterozygote comparison (AA vs Aa), a dominant model and a recessive model between groups. In this study, the dominant model was defined as Aa+aa vs AA, where "A" and "a" are major and minor alleles, respectively, and the recessive model as aa $v s \mathrm{AA}+\mathrm{Aa}$. The distribution of genotypes in the studies included was tested for HWE using the $\chi^{2}$ test. Between-study heterogeneities were estimated using the $\mathrm{I}^{2}$ test. $\mathrm{I}^{2}$ represents the variability that can be attributed to heterogeneity rather than chance. $\mathrm{I}^{2}$ values of 25,50 , and $75 \%$ were defined as low, moderate and high estimates, respectively. When a significant $\mathrm{I}^{2}>50 \%$ indicated heterogeneity across studies, the random effects model was used for meta-analysis, or else the fixed effects model was used. Sensitivity analysis was performed using random effect model values compared to the fixed effect. The Begg test was used to obtain evidence of publication bias, which was shown as a funnel plot ( $\mathrm{P}<0.05$ was considered to be statistically significant).

\section{RESULTS}

\section{Study characteristics}

Through screening the title and reading the abstract and the entire article, 6 eligible articles were selected for this meta-analysis (Figure 1). For the $3801 \mathrm{~T}>\mathrm{C}$ polymorphism, 5 studies were available, including a total of 731 cases and 1059 controls. For the A2455G polymorphism, 4 studies involved a total of 1474 cases and 1662 controls. The publishing year of the studies included ranged from 1995 to 2014. All the articles were written in English. The source of controls was mainly based on healthy populations. The HWE test was performed on genotype distribution of the controls, all of them were in HWE $(\mathrm{P}>0.05)$ except in the study by Imaizumi et al. (2009). The baseline characteristics and methodological quality of all studies included are summarized in Table 1.

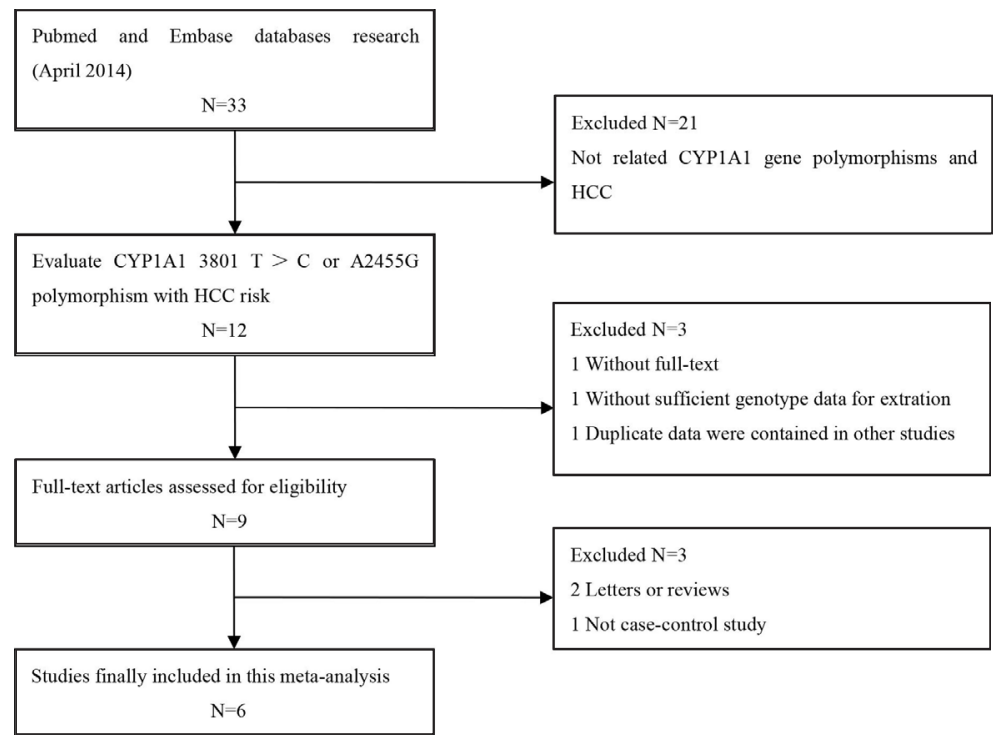

Figure 1. Flow chart showing study selection procedure. 


\section{Quantitative synthesis}

The evaluation of the association between the $3801 \mathrm{~T}>\mathrm{C}$ polymorphism and the risk of HCC is displayed in Figure 2 and Table 2. Meta-analysis results showed significant associations between the $3801 \mathrm{~T}>\mathrm{C}$ polymorphism and $\mathrm{HCC}$ risk $(\mathrm{TT}$ vs $\mathrm{CC}: \mathrm{OR}=1.21,95 \% \mathrm{CI}=$ $0.63-2.30$; TT $v_{s}$ TC: $\mathrm{OR}=0.87,95 \% \mathrm{CI}=0.55-1.38$; dominant model: $\mathrm{OR}=1.03,95 \% \mathrm{CI}=$ $0.62-1.71$; recessive model: $\mathrm{OR}=1.33,95 \% \mathrm{CI}=0.89-1.98$ ). In the subgroup analysis based on ethnicity, the results of subgroup analysis confirmed that there was significant associations between $3801 \mathrm{~T}>\mathrm{C}$ and $\mathrm{HCC}$ risk in Asian populations (TT vs $\mathrm{CC}$ : $\mathrm{OR}=0.94,95 \% \mathrm{CI}=0.57$ 1.55 ; TT vs TC: $\mathrm{OR}=0.77,95 \% \mathrm{CI}=0.60-0.99$; dominant model: $\mathrm{OR}=1.26,95 \% \mathrm{CI}=0.86$ 1.84; recessive model: $\mathrm{OR}=1.25,95 \% \mathrm{CI}=0.97-1.63$ ). Sensitivity analysis was performed by omission of one non-HWE study and the result was not altered, indicating the result of meta-analysis was statistically significant (Table 2).

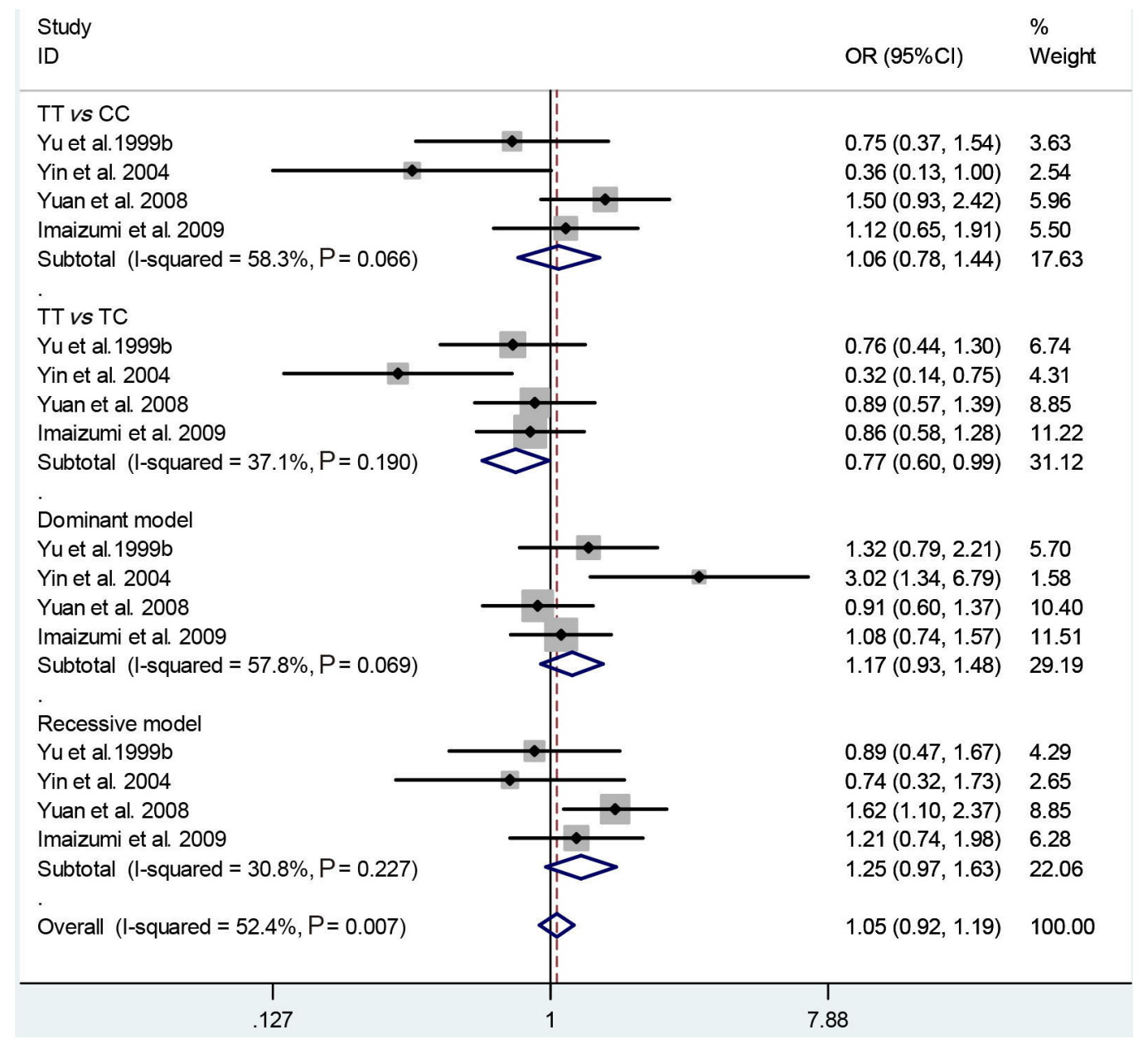

Figure 2. Meta-analysis of the relationship between the $3801 \mathrm{~T}>\mathrm{C}$ polymorphism and HCC risk in Asians. 
Table 2. Summary ORs and $95 \% \mathrm{CI}$ of CYP1A1 gene $3801 \mathrm{~T}>\mathrm{C}$ polymorphism and HCC risk.

\begin{tabular}{|c|c|c|c|c|c|c|c|c|c|}
\hline \multirow[t]{2}{*}{ Subgroup } & \multirow[t]{2}{*}{ Genetic model } & \multirow{2}{*}{$\begin{array}{l}\text { Sample size } \\
\overline{\text { Case/control }}\end{array}$} & \multirow[t]{2}{*}{ Type of model } & \multicolumn{2}{|c|}{$\begin{array}{c}\text { Test of } \\
\text { heterogeneity }\end{array}$} & \multicolumn{2}{|c|}{$\begin{array}{c}\text { Test of } \\
\text { association }\end{array}$} & \multicolumn{2}{|c|}{$\begin{array}{c}\text { Test of } \\
\text { publication bias }\end{array}$} \\
\hline & & & & $\mathrm{I}^{2}$ & $\mathrm{P}$ & $\overline{\mathrm{OR}}$ & $95 \% \mathrm{CI}$ & $\mathrm{z}$ & $\mathrm{P}$ \\
\hline \multirow[t]{4}{*}{ Overall } & TT vs CC & \multirow[t]{4}{*}{$731 / 1059$} & Random & $77.3 \%$ & 0.00 & 1.21 & $0.63-2.30$ & 0.00 & 1.00 \\
\hline & $\mathrm{TT} v s \mathrm{TC}$ & & Random & $71.2 \%$ & 0.00 & 0.87 & $0.55-1.38$ & 0.00 & 1.00 \\
\hline & Dominant model & & Random & $79.4 \%$ & 0.00 & 1.03 & $0.62-1.71$ & 0.00 & 1.00 \\
\hline & Recessive model & & Random & $54.9 \%$ & 0.06 & 1.33 & $0.89-1.98$ & 0.00 & 1.00 \\
\hline \multirow[t]{4}{*}{ Asians } & $\mathrm{TT} v s \mathrm{CC}$ & \multirow[t]{4}{*}{$640 / 963$} & Random & $58.3 \%$ & 0.07 & 0.94 & $0.57-1.55$ & 0.34 & 0.73 \\
\hline & $\mathrm{TT} v s \mathrm{TC}$ & & Fixed & $37.1 \%$ & 0.19 & 0.77 & $0.60-0.99$ & 0.34 & 0.73 \\
\hline & Dominant model & & Random & $57.8 \%$ & 0.07 & 1.26 & $0.86-1.84$ & 0.34 & 0.73 \\
\hline & Recessive model & & Fixed & $30.8 \%$ & 0.23 & 1.25 & $0.97-1.63$ & 0.34 & 0.73 \\
\hline \multirow{4}{*}{$\begin{array}{l}\text { Consistent with } \\
\text { HWE }\end{array}$} & TT vs CC & \multirow[t]{4}{*}{$522 / 803$} & Random & $82.8 \%$ & 0.00 & 1.22 & $0.50-3.02$ & 0.34 & 0.73 \\
\hline & $\mathrm{TT} v s \mathrm{TC}$ & & Random & $78.3 \%$ & 0.00 & 0.87 & $0.46-1.65$ & 0.34 & 0.73 \\
\hline & Dominant model & & Random & $84.4 \%$ & 0.00 & 1.03 & $0.50-2.11$ & 0.34 & 0.73 \\
\hline & Recessive model & & Random & $65.0 \%$ & 0.04 & 1.36 & $0.79-2.35$ & 0.34 & 0.73 \\
\hline
\end{tabular}

The combined results of $\mathrm{A} 2455 \mathrm{G}$ polymorphism and $\mathrm{HCC}$ risk are summarized in Figure 3 and Table 3. Meta-analysis results identified no significant association between A2455G polymorphism and susceptibility to $\mathrm{HCC}$ (AA vs $\mathrm{GG}$ : $\mathrm{OR}=1.43,95 \% \mathrm{CI}=0.74-$ 2.75; AA vs AG: $\mathrm{OR}=1.07,95 \% \mathrm{CI}=0.92-1.25$; dominant model: $\mathrm{OR}=0.84,95 \% \mathrm{CI}=0.61$ 1.17; recessive model: $\mathrm{OR}=1.32,95 \% \mathrm{CI}=0.79-2.19$ ). In the subgroup analysis by ethnicity, we detected no significant association between $\mathrm{A} 2455 \mathrm{G}$ polymorphism and $\mathrm{HCC}$ risk (AA vs GG: $\mathrm{OR}=1.21,95 \% \mathrm{CI}=0.88-1.67$; AA $v s \mathrm{AG}: \mathrm{OR}=1.02,95 \% \mathrm{CI}=0.87-1.20$; dominant model: $\mathrm{OR}=1.95,95 \% \mathrm{CI}=0.82-1.11$; recessive model: $\mathrm{OR}=1.20,95 \% \mathrm{CI}=0.88-1.65$ ). Sensitivity analyses were conducted by altering the statistical models. No material alteration was detected, indicating that our results were statistically robust.

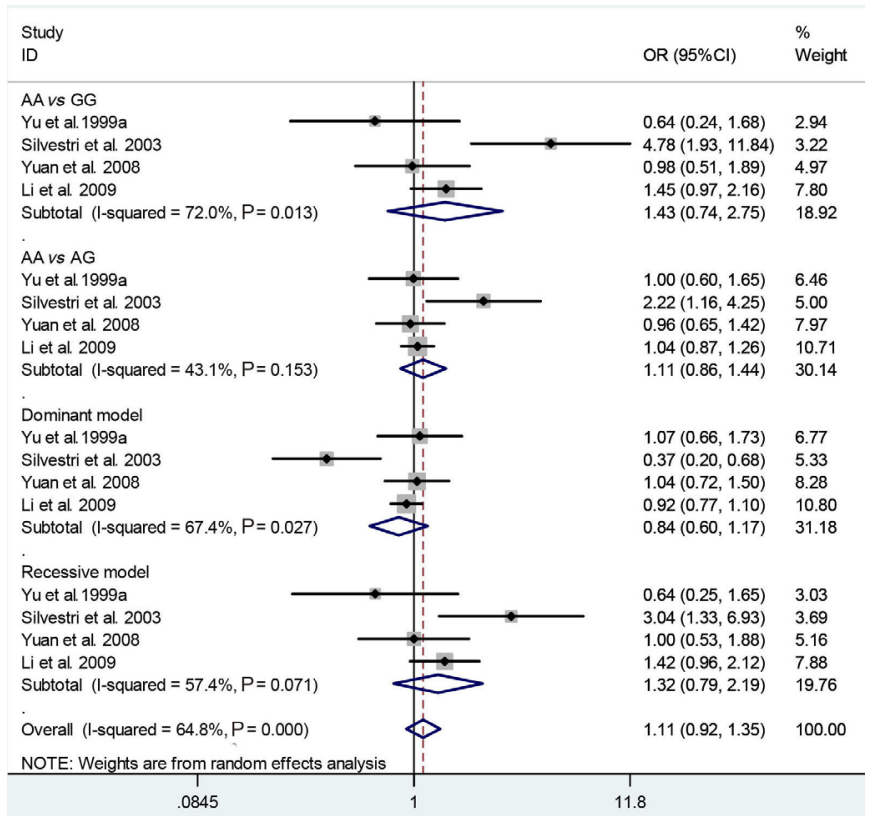

Figure 3. Meta-analysis of the relationship between the $\mathrm{A} 2455 \mathrm{G}$ polymorphism and $\mathrm{HCC}$ risk in the total population. 
Table 3. Summary ORs and $95 \% \mathrm{CI}$ of CYP1A1 gene A2455G polymorphism and HCC risk.

\begin{tabular}{|c|c|c|c|c|c|c|c|c|c|}
\hline \multirow[t]{2}{*}{ Subgroup } & \multirow[t]{2}{*}{ Genetic model } & \multirow{2}{*}{$\begin{array}{l}\text { Sample size } \\
\text { Case/control }\end{array}$} & \multirow[t]{2}{*}{ Type of model } & \multicolumn{2}{|c|}{$\begin{array}{c}\text { Test of } \\
\text { heterogeneity }\end{array}$} & \multicolumn{2}{|c|}{$\begin{array}{c}\text { Test of } \\
\text { association }\end{array}$} & \multicolumn{2}{|c|}{$\begin{array}{c}\text { Test of } \\
\text { publication bias }\end{array}$} \\
\hline & & & & $\mathrm{I}^{2}$ & $\mathrm{P}$ & OR & $95 \% \mathrm{CI}$ & $\mathrm{z}$ & $\mathrm{P}$ \\
\hline \multirow[t]{4}{*}{ Overall } & $\mathrm{AA} v s \mathrm{GG}$ & $1474 / 1662$ & Random & $72.0 \%$ & 0.01 & 1.43 & $0.74-2.75$ & 0.34 & 0.73 \\
\hline & $\mathrm{AA} v s \mathrm{AG}$ & & Fixed & $43.1 \%$ & 0.15 & 1.07 & $0.92-1.25$ & 0.34 & 0.73 \\
\hline & Dominant model & & Random & $67.4 \%$ & 0.03 & 0.84 & $0.61-1.17$ & 0.34 & 0.73 \\
\hline & Recessive model & & Random & $57.4 \%$ & 0.07 & 1.32 & $0.79-2.19$ & 0.34 & 0.73 \\
\hline \multirow[t]{4}{*}{ Asians } & $\mathrm{AA} v s \mathrm{GG}$ & $1384 / 1563$ & Fixed & $28.9 \%$ & 0.25 & 1.21 & $0.88-1.67$ & 0.34 & 0.73 \\
\hline & $\mathrm{AA} v s \mathrm{AG}$ & & Fixed & $0.0 \%$ & 0.92 & 1.02 & $0.87-1.20$ & 0.34 & 0.73 \\
\hline & Dominant model & & Fixed & $0.0 \%$ & 0.75 & 1.95 & $0.82-1.11$ & 0.34 & 0.73 \\
\hline & Recessive model & & Fixed & $26.4 \%$ & 0.26 & 1.20 & $0.88-1.65$ & 0.34 & 0.73 \\
\hline
\end{tabular}

\section{Publication bias}

Publication bias of the literature was assessed by the Begg funnel plot. The Begg funnel plot was used to measure the asymmetry of the funnel plot. The results of the Begg funnel plot test are shown in Tables 2 and 3, and showed that there was no publication bias (all $\mathrm{P}>0.05$ ).

\section{DISCUSSION}

CYPs are a superfamily of mixed-function monooxygenases encoded by at least 50 different genes grouped in 10 families, which are mainly expressed in the liver. The CYP1, CYP2, and CYP3 family genes are located in the endoplasmic reticulum, and their major role is the metabolism of xenobiotics (Nebert et al., 1987). CYP1A1 is a member of the CYP1 family and participates in the metabolism of a vast number of xenobiotics, which may well lead to their activation, and in the case of CYP1A1, the activation of benzo[a]pyrene is a wellstudied reaction (Androutsopoulos et al., 2009). CYP1A1 plays a key role in phase I metabolism of polycyclic aromatic hydrocarbons and in estrogen metabolism, and the dysfunction of CYP1A1 can cause the damage to DNA, lipids, and proteins, which further result in carcinogenesis (Nebert et al., 2006). In addition, CYP1A1 polymorphisms have been implicated as genetic modifiers of cancer risk in different tumor models, and a few studies have also specifically investigated their role in HCC development.

In the past decade, a number of molecular epidemiological studies have been done to evaluate the association between CYP1A1 T3801C and A2455G polymorphism and HCC risk. However, the results were inconsistent or even contradictory. Partially because of the possible small effect of the polymorphism on cancer risk and the relatively small sample size in each of the studies published. To help clarify the controversial finding, a meta-analysis was performed to obtain a more competitive result by combining the comparable studies, increasing the sample size and statistical power. Finally, the results of our meta-analysis showed no significant association between the CYP1A1 $3801 \mathrm{~T}>\mathrm{C}$ polymorphism and HCC risk. Because of differences in genetic background and home environment, we performed an ethnicity-specific subgroup analysis and found a significant association between $3801 \mathrm{~T}>\mathrm{C}$ polymorphism and HCC risk in Asians. Since only one study was performed in Europe, the results of subgroup analysis by ethnicity could not be reliable for Europeans. As for A2455G, the meta-analysis indicated no significant association between the CYP1A1 A2455G polymorphism and HCC risk. There was no evidence of publication bias in this meta-analysis (all $P>0.05$ ). Since the 
eligible study number was limited in the meta-analysis, these results still need to be validated by further investigation.

The mechanism of how CYP1A1 $3801 \mathrm{~T}>\mathrm{C}$ polymorphism relates to $\mathrm{HCC}$ risk is still unclear. Possible reason is that the $3801 \mathrm{~T}>\mathrm{C}$ polymorphism can alter the level of gene expression or messenger RNA stability, resulting in highly inducible CYP1A activity. In addition, the potential function of $3801 \mathrm{~T}>\mathrm{C}$ polymorphism may be affected via gene-gene and gene-environment interactions. A previous study demonstrated that the $p 53$ codon 72 polymorphism and CYP1A1 $3801 \mathrm{~T}>\mathrm{C}$ polymorphism synergistically increased $\mathrm{HCC}$ risk (Yu et al., 1999b). Also, cigarette smoking is a major nonviral risk factor for HCC, where smokers with $3801 \mathrm{~T}>\mathrm{C}$ polymorphism alleles are more susceptible to HCC (Yu et al., 1999b). Since one study could not be included in our meta-analysis, further studies of gene-gene interactions should be taken into consideration for assessment of HCC risk.

Some limitations of our meta-analysis should be addressed. First, because of incomplete raw data, some relevant studies could not be included in our analysis. Second, our metaanalysis was based on unadjusted data. Third, the genotype information stratified for the main confounding variables was not available in the original papers and the confounding factors addressed across the different studies were variable.

In conclusion, our meta-analysis indicated that CYP1A1 $3801 \mathrm{~T}>\mathrm{C}$ polymorphism may be associated with increased risk of $\mathrm{HCC}$ in Asians. Considering the limitations of the present meta-analysis, it is necessary to conduct further research with standardized unbiased methods, larger sample studies and well-matched controls.

\section{Conflicts of interest}

The authors declare no conflict of interest.

\section{REFERENCES}

Androutsopoulos VP, Tsatsakis AM and Spandidos DA (2009). Cytochrome P450 CYP1A1: wider roles in cancer progression and prevention. BMC Cancer 9: 187.

Guengerich FP and Shimada T (1998). Activation of procarcinogens by human cytochrome P450 enzymes. Mutat. Res. 400: 201-213.

Imaizumi T, Higaki Y, Hara M, Sakamoto T, et al. (2009). Interaction between cytochrome P450 1A2 genetic polymorphism and cigarette smoking on the risk of hepatocellular carcinoma in a Japanese population. Carcinogenesis 30: 17291734.

Li R, Shugart YY, Zhou W, An Y, et al. (2009). Common genetic variations of the cytochrome P450 1A1 gene and risk of hepatocellular carcinoma in a Chinese population. Eur. J. Cancer 45: 1239-1247.

Liu S, An J, Lin J, Liu Y, et al. (2014) Single nucleotide polymorphisms of MicroRNA processing machinery genes and outcome of hepatocellular carcinoma. PLoS One 9: e92791.

Nebert DW and Gonzalez FJ (1987). P450 genes: structure, evolution, and regulation. Annu. Rev. Biochem. 56: 945-993.

Nebert DW and Dalton TP (2006). The role of cytochrome P450 enzymes in endogenous signalling pathways and environmental carcinogenesis. Nat. Rev. Cancer 6: 947-960.

Niwa Y, Matsuo K, Ito H, Hirose K, et al. (2005). Association of XRCC1 Arg399Gln and OGG1 Ser326Cys polymorphisms with the risk of cervical cancer in Japanese subjects. Gynecol. Oncol. 99: 43-49

Parkin DM, Bray F, Ferlay J, Pisani P, et al. (2001). Estimating the world cancer burden: GLOBOCAN 2000. Int. J. Cancer 94: 153-156.

Rodriguez-Antona C and Ingelman-Sundberg M (2006). Cytochrome P450 pharmacogenetics and cancer. Oncogene 25: 1679-1691.

Shah PP, Saurabh K, Pant MC, Mathur N, et al. (2009). Evidence for increased cytochrome P450 1A1 expression in blood lymphocytes of lung cancer patients. Mutat. Res. 670: 74-78. 
Shimada T (2006). Xenobiotic-metabolizing enzymes involved in activation and detoxification of carcinogenic polycyclic aromatic hydrocarbons. Drug Metab. Pharmacokinet 21: 257-276.

Silvestri L, Sonzogni L, De Silvestri A, Gritti C, et al. (2003). CYP enzyme polymorphisms and susceptibility to HCVrelated chronic liver disease and liver cancer. Int. J. Cancer 104: 310-317.

Yin PH, Lee HC, Chau GY, Liu TY, et al. (2004). Polymorphisms of estrogen-metabolizing genes and risk of hepatocellular carcinoma in Taiwan females. Cancer Lett. 212: 195-201.

Yu MW, Chiu YH, Yang SY, Santella RM, et al. (1999a). Cytochrome P450 1A1 genetic polymorphisms and risk of hepato cellular carcinoma among chronic hepatitis B carriers. Br. J. Cancer 80: 598-603.

Yu MW, Yang SY, Chiu YH, Chiang YC, et al. (1999b). A p53 genetic polymorphism as a modulator of hepatocellular carcinoma risk in relation to chronic liver disease, familial tendency, and cigarette smoking in hepatitis B carriers. Hepatology 29: 697-702.

Yuan X, Zhou G, Zhai Y, Xie W, et al. (2008). Lack of association between the functional polymorphisms in the estrogenmetabolizing genes and risk for hepatocellular carcinoma. Cancer Epidemiol. Biomarkers Prev. 17: 3621-3627.

Zhan P, Wang Q, Qian Q, Wei SZ, et al. (2011). CYP1A1 MspI and exon7 gene polymorphisms and lung cancer risk: an updated meta-analysis and review. J. Exp. Clin. Cancer Res. 30: 99. 